\title{
STARZ-DRP AS A TRIAGING TOOL FOR COMMUNITY PHARMACISTS: PERSPECTIVES AND EXPECTATIONS OF STAKEHOLDERS
}

\author{
NAZRI NORDIN*, MOHAMED AZMI AHMAD HASSALI, AZMI SARRIFF \\ School of Pharmaceutical Sciences, Universiti Sains Malaysia, 11800 Minden, Pulau Pinang, Malaysia \\ Email: nazri@i-raey.com
}

Received: 21 Jun 2017 Revised and Accepted: 21 Sep 2017

\begin{abstract}
Objective: To investigate perspectives and expectations of stakeholders of community pharmacists' (CPs) roles and the use of STARZ-DRP as a structured and systematic framework to help CPs to extend their role to make an accurate triage decision in community pharmacy settings.

Methods: Individuals who were in high positions in the Ministry of Health (MOH), pharmacy, medical and consumer associations and individuals who were a private medical practitioner and retail pharmacist were invited via mail to participate in the face to face interview. The interviews were
\end{abstract} audio-taped and transcribed verbatim to identify themes as many as possible.

Results: Eight stakeholders had responded to the invitation. Mean ( \pm standard deviation) age (years) of stakeholders was $56.50 \pm 11.82$. Five themes were noted which were: (i) CPs are focusing more on business-oriented, (ii) CPs shall perform patient-oriented services, (iii) responsibilities to triage customers, (iv) a systematic approach for triaging activities, (v) STARZ-DRP as a systematic approach to making triage decision.

Conclusion: CPs are paying particular attention to business-oriented than patient-oriented services. All stakeholders point out that CPs should intensify their current practice and all of them have the same opinion that CPs should take the responsibilities to make an accurate triage decision for self-care customers. Almost all stakeholders agree that STARZ-DRP is an ideal framework to help CPs to make an accurate triage decision in community pharmacy settings.

Keywords: STARZ-DRP, Community pharmacists, Triage decision, Stakeholders, Malaysia

(c) 2017 The Authors. Published by Innovare Academic Sciences Pvt Ltd. This is an open access article under the CC BY license (http://creativecommons.org/licenses/by/4.0/) DOI: http://dx.doi.org/10.22159/ijpps.2017v9i11.20876

\section{INTRODUCTION}

Globally, a variety of health information and communication facilities are easily accessible via the internet. People can search information about a disease which is affecting their body and mind and medical therapy used to treat the disease. Consequently, they shall have a potential to take an opportunity to perform self-diagnosis and selfmedicating behaviour [1] without seeking expert advice from the general practitioners (GPs) [2]. It is even worse when they can easily buy over-the-counter medications, supplements or vitamins in community pharmacies, medical stalls or groceries $[2,3]$. Currently, this trend of behaviour is well accepted around the world [1-3].

Even though the behaviour is noted to save money and time $[4,5]$, it has potential to harm the people [6]. For example, misuse of nonsteroidal anti-inflammatory drugs is potentially noted to cause damage to the gastroduodenal mucosa via several mechanisms [7]. Therefore, the community pharmacists (CPs) shall take the responsibilities to educate self-care customers about the possibility of suffering physical harm due to improper self-diagnosis and selfmedicating behaviour [8]. Having such a duty to give professional advice to self-care customers has been noted in other countries. It is noted that CPs are offering advice to the customers to select the best medication to treat their medical problem or referring them to GPs when necessary $[2,3]$. The event reflects CPs can perform the responsibilities to be in charge of their customers' self-diagnosis and self-medicating behaviour.

However, it is noted that CPs in Malaysia are paying particular attention to products as the first priority in their practice, followed by customers [9]. Potential barriers noted that restrain CPs from performing additional services are a lack of clinical knowledge, skills, and training [10-12]. Such barriers must be intervened so that CPs can perform the role to advocate self-care customers. However, it is believed that such a role requires a framework to show the way to determine their customer medical problem and pinpoint risk factors which might need high-priority of medical attention [13].
Another way to say, the framework shall help CPs to distinguish if the medical problem requires: (i) pharmacist-only medication, supplements or vitamins, (ii) immediate medical attention or prescription-only medications, (iii) health-screening or dietary advice. Such activities are known as triage decision. This term was noted earlier since World War One when the officers had to determine about casualties of war: (i) able to travel home, (ii) require immediate surgery, (iii) left to die [14]. STARZ-DRP has been picked out as the most appropriate framework to help CPs to make an accurate triage decision for self-care customers [15].

Each word as depicted in table 1 stands for a specific analysis of medical and medication histories. STARZ-DRP has engaged in a validation study involving eleven GPs and nineteen CPs [16].

The aims of this study are to investigate the stakeholders' perspectives and expectations of CPs' roles and STARZ-DRP as a framework to help CPs to make an accurate triage decision for selfcare customers. The rationale of this study is the fact that it might provide information for the policymakers to have some ideas about CPs' potential extended roles and justify the use of STARZ-DRP as a counselling framework for CPs to advocate self-care customers.

\section{MATERIALS AND METHODS}

\section{Study design}

A semi-structured interview was carried out to assemble verbal data from the stakeholders. A set of questionnaires as depicted in table 2 was drafted as a blueprint for the interviewer to solicit the stakeholders' perspectives and expectations of CPs' role and STARZDRP as a framework to help CPs to advocate self-care customers. The questionnaires had been justified earlier for its competency. A few candidates were listed as stakeholders after thoroughly meeting among the researchers. Main criteria were illustrated in table 3. All candidates were approached via mail using the Dillman's Method as a modus operandi to invite them to the study [17]. They were entreated to give their feedback within $2 \mathrm{w}$. Those who neglected to 
give a feedback within $2 \mathrm{w}$ were approached via mail once more. Failure to give a feedback to the invitation letter after $8 \mathrm{w}$ was discarded from participating in the study. The short-listed candidates who were approached via mail were:

1) Deputy Minister, MOH Malaysia

2) Director, Pharmacy Practice and Development Division, Pharmaceutical Services Division, MOH Malaysia

3) President, Malaysian Medical Association (MMA)

4) Chairman, MMA (Penang Branch)

5) President, Penang Medical Practitioner's Society (PMPS)

6) President, Malaysian Pharmaceutical Society (MPS)

7) President, Malaysian Community Pharmacy Guild (MCPG)

8) Chairman, MPS (Penang branch)

9) Chairman, MCPG (Northern branch)
10) President, Consumers Association of Penang (CAP)

11) Private medical practitioner

12) Retail pharmacist

The interview sessions were carried out within the period of $1^{\text {st }}$ August 2015 and 31 3 st May 2016 which date, time and location were determined after initial contact via phone-call and acquired written consents from the stakeholders. Throughout the interviews, the interviewer was using probing questions when necessary. At the end of the interview session, the stakeholders were allowed to point out extra tips, proposal or ideas regarding matters in question. The interview sessions were carried out in English, audio-taped and transcribed verbatim. Afterward, the researchers were carefully listening to the tapes, word by word to verify the transcripts for their accuracy. Then the transcripts were analysed line by line to pinpoint themes as many as possible [18]. The interview was repeated until there was no more perspective or expectation emerged. This study had been approved by the Human Research Committee USM (USM/JEPeM/15040145).

Table 1: Definition of letters in STARZ ${ }^{\#^{*}}$

\begin{tabular}{ll}
\hline Letter & Description \\
\hline $\mathrm{S}$ & Symptom presentation refers to subjective evidence of health problem perceived by the patient. \\
$\mathrm{T}$ & Time of onset and duration of the present symptoms. \\
$\mathrm{A}$ & Associated symptoms refer to patient symptoms explored and determined by the pharmacist during the interview. It does not refer to the \\
& symptoms presented earlier by the patient. This is done by using the pictorial documentation form. To aid and ease the pharmacist during \\
& the interview, the human body is arbitrarily divided into four regions: (i) Front: the part of the body facing the pharmacist (asking for \\
& symptoms like bloating, heartburn, nausea, vomiting, breathlessness, extra), (ii) Back (asking for symptoms like lower and upper back \\
& pain, shoulder pain, and neck pain), (iii) Upper (head) (asking for symptoms like headache, dizziness, problems with sleep, extra), (iv) \\
& Lower (asking for symptoms like numbness in both legs and hands, constipation, and swollen feet). Perhaps, the method is likened to a \\
& filtering or screening process to rule out the presence of severe symptoms. \\
& Recurrence problem refers to the symptoms have been treated before, specifically when the symptoms recur and persist despite the \\
& treatment prescribed. \\
R & Zoom into the patient's medication experience refers to information collected by the pharmacist related to any medical problems \\
& (example, hypertension, diabetes, hyperthyroid, extra), medication utilization (example, use of prescription and non-prescription drugs, \\
and herbal supplements), immunization history, allergies, drug sensitivities, drug side effects, adverse reactions, and the consumption of &
\end{tabular}

\#This is not a diagnostic tool, rather it is a format with the purpose of organizing a community pharmacist's knowledge in a manner that allows him/her to begin identifying the actual and potential drug-related problems and subsequently referring triage patients to the appropriate healthcare professionals. *The patient's vital signs will be measured when necessary. At times, the patient's blood pressure, pulse rate, and body temperature are measured to aid the pharmacist in assessing the appropriateness of symptoms for self-medication.

\section{Table 2: Interview-questionnaire}

Q1. What is the current role of community pharmacist in our health-care system?

Q2. Do you think that the community pharmacist can do more than what they are doing right now?

Q3. Are you familiar with the term 'triaging-decision'?

Q4. Do you think that 'triaging activities' at the community pharmacy settings shall have a systematic approach?

Q5. Do you think that 'STARZ-DRP' is a systematic approach to make triaging-decision?

Table 3: Main criteria for inclusion to the study

\begin{tabular}{ll}
\hline Population & $\begin{array}{l}\text { Deputy Minister (MOH), director (pharmacy practice and development division, MOH), president or chairman of medical or } \\
\text { pharmacy or consumer association, private medical practitioner, retail pharmacist }\end{array}$ \\
& High ranking officers in $\mathrm{MOH}$; \\
& High ranking representative in the associations; \\
& Have knowledge about CPs' activities; \\
& Experience in practice for more than $10 \mathrm{y}$ (exclusive for a private medical practitioner and retail pharmacist). \\
\hline
\end{tabular}

$\mathrm{MOH}=$ Ministry of Health; CPs=Community pharmacists

\section{RESULTS}

There were eight candidates who had given their feedback to the invitation letter via mail. The respondents were:

1) Director, Pharmacy Practice and Development Division, Pharmaceutical Services Divisions, MOH Malaysia
2) President, MPS

3) President, MCPG

4) Chairman, MPS (Penang branch)

5) Chairman, MCPG (Northern branch) 
6) Vice President, CAP

7) Private medical practitioner

8) Retail pharmacist
Majority of the stakeholders were engaged in face to face interview. However, one of the stakeholders had requested the interview to be carried out via phone-call. The demographic data of the stakeholders was illustrated in table 4.

Table 4: Demographic data of stakeholders

\begin{tabular}{ll}
\hline Characteristics & Participants, $\mathbf{n = 8}$ \\
\hline${ }^{* *}$ Age & \\
(mean \pm Standard Deviation) & $56.50 \pm 11.82$ \\
Gender & \\
Female & $37.5 \%$ \\
Male & $62.5 \%$ \\
Race & \\
Malay & $50.0 \%$ \\
Chinese & $37.5 \%$ \\
Other & $12.5 \%$ \\
${ }^{* * *}$ Interview session & \\
mean \pm Standard Deviation & $28.25 \pm 6.92$ \\
\hline
\end{tabular}

${ }^{*} \mathrm{n}=$ number of participants; * ${ }^{* *}$ ge in years; ${ }^{* * *}$ Interview session in minutes.

The thematic content analysis yielded five major themes: (i) CPs are focusing more on business-oriented practice, (ii) CPs shall perform patient-oriented services, (iii) responsibilities to triage customers, (iv) a systematic approach for triaging activities, (v) STARZ-DRP as a systematic approach to making triage decision.

\section{Theme 1: CPs are focusing more on business-oriented practice}

Majority of the stakeholders $(n=5)$ pointed out that CPs were currently paying particular attention to business-oriented or product-oriented services in community pharmacy settings.

"Actually, I am not familiar with the term CPs because in Malaysia those CPS are not really known to everybody. Actually, I do not have any ideas about the role of CPs. Otherwise, I will say that CPs are more like a business-oriented practice, selling medication, controlled or noncontrolled, prescription or non-prescription. Not really serving the community in term of giving a lot of advice and no vision to promote health and so on. I see now like very competitive, like a retail shop or grocery shop. Everybody is competing for price; price war is everywhere especially in Penang" (P1)

"As you know our system at this moment, we do not have dispensing separation. If you look at most CPs, we are sustaining with whatever we can to maintain our business" (P4)

Main reason pointed out by the stakeholders for such particular attention was the dispensing separation issue. Such an issue had averted CPs for many years from performing a wide range of patient-oriented services in community pharmacy settings.

"Based on what is going on in this country, the real truth is the fact that they are still practicing as a retail pharmacist. So MPS itself is trying to change. We know that the government keens to think the role of retail pharmacists to become CPs. But it will only go as a plan. It is not executed as how. So, I think the most important thing engagement. So, I have been as the MPS counsel for the last one and a half year, and I too have concerned into the community pharmacy's practice. It is actually related to the dispensing separation issue. So, I think the first step we need to do is actually sort out of convert the current practice from the retail perspective to additional of CPs. So, actually, we remove the word retail pharmacist. So, we are not addressing retail pharmacists. At the same time, we also want the people to change" (P5)

"The current role of CPs is unsatisfactory. Mostly because of the government's legislative problem, whereby CPs are not given a proper role to do especially in the area of prescription issues by the doctor because without the prescription for the private community pharmacies a lot of our professional roles cannot be carried out example like screening the prescriptions, detection of the drug interaction, advising the patients of the proper usage. Many of the conditions cannot be done. There is an unfortunate case. There is a reason why many of us in the community such as MCPG and MPS having fighting hard for this dispensing separation. Without the dispensing separation, the professional role of CPs will not be satisfactory. We can develop our own role, we can do counter dispensing, but that is the usual the conventional role for the community pharmacy" (P8)

Nevertheless, the stakeholders P2, P3, and P6 were still portraying $\mathrm{CPs}$ as a potential healthcare provider in the healthcare system.

"CPs are actually to educate the public, to teach them how to use medicine correctly and then what are medicines that they can refer to the doctor when necessary whether they can buy the medication, they can treat themselves or they need some specialists to diagnose the disease" (P3)

"By right CPs should be executing a role managing minor ailments, helping patients in term of wellness so that they can help to reduce the healthcare cost. Then patients or public can go to the community pharmacy and it will reduce the burden in the government sector for minor ailments and even in the private sectors. So, this is the way CPS should improve themselves and try to play a role in these two areas" (P6)

\section{Theme 2: CPs shall perform patient-oriented services}

All stakeholders had the same opinion that CPs should take the responsibilities to provide a wide range of patient-oriented services in community pharmacy settings.

"Yes. When they are trained, why not. With knowledge and skill, they can provide patient-oriented service. For example, nobody wants to go to the hospital to wait for a doctor for two to three hours just for cold, they just go to the nearby pharmacy and tell 'I have a cold, please give me something'. If the pharmacist is trained, have the knowledge, to give something for a cold. The cold, what are you doing if you see a doctor also, they just feel your pulse, even that they do not do nowadays. They just give a commercial bottle of medicine to take. I think it is matter of training" (P7)

"We do more than that. In fact, we are putting the other way around. We are already doing beyond the dispensing of the medicine. We are already doing the managing of the condition but the thing is that it is not an ideal practice. An ideal practice, we need to start off with our fundamental. Fundamental which is to see what the doctors have diagnosed for the patient, what they have prescribed the treatment inside the prescription sheet for the patient. From there we are going beyond it. We go beyond the dispensing of the prescription. We go into the medication management review plus the other when there is a programme supplement to doctors to prescribe. Now the real situation is we are doing the second part without the first part. We should be 
doing the same thing as what the pharmacists in the government sector, government hospitals are doing. Doing the first part first, after that we proceed to the second part. So, my answer is definitely we are away beyond the dispensing. The answer is dispensing is not the only role that CPs are trying and should do. Dispensing is the fundamental thing we need to do. But we need to go beyond it. Because dispensing itself is insufficient to sustain the community pharmacy practice" (P8)

However, stakeholder P5 had pointed out that CPs should become a member of MPS and MCPG before they could perform a wide range of patient-oriented services.

"CPs do not practice. They have to be a member of professional body like MPS and MCPG to provide professional services" (P5)

Whereas, stakeholder P1 had pointed out that CPs should wipe out 'price war' event before CPs could perform patient-oriented services.

"I think that during their school time they had been taught of their pharmacy professionalism how to serve the community, the ethics and other issues, not just a business. My advice to them, be practiced what had been taught. Not only look at a business side of equally. But now they do focus on this. CPS should extend their role to more patientoriented practice. Maybe one way of doing this is, we should control the price, the price of the medication should be fixed at one recommending price so that nobody is fighting price, competing with each other. We have eliminated the aspect of business competition at one point. When this is handled with, so they can focus on other things like the one said just now, extend the role to more patient-oriented practice" (P1)

\section{Theme 3: Responsibilities to triage customers}

It was noted that stakeholders P2, P3, P4, and P7 did not have an idea about the term was known as triage decision. Once they acquired a knowledge of triage decision, the stakeholders had the same opinion that CPs should take the responsibilities to make an accurate triage decision for their customers.

"Definitely. There is a certain role that we play. That is why it is good that we can identify what is the pharmacist's role and what is the doctor's role. I agree with triaging" (P2)

"This is usually what we did now" (P3)

"This is very important. In my experience $18 y$ as a pharmacist, this is what I do. Skin issue, symptoms that appear superficially asked. It is something, it is the area that pharmacists must master. To differentiate fungal skin, to differentiate eczema with psoriasis, dermatitis to know the varieties cream that needs to apply, medication that you need to take, to differentiate the root cause of the problem, very important. Because in my 18 y I have seen a lot of customers are coming and said they have seen all specialists and the problem doesn't go. If the pharmacist is knowledgeable in finding out what the root cause is, they can actually solve it with a simple supplement and simple cream and the problem will disappear. I totally support this because managing sign and symptom of walking customers is very important, to do the right diagnosis, to do the right referral, for the patients" (P4)

\section{"The pharmacists must know about this. It is knowledge" (P7)}

However, stakeholder P8 had pinpointed the term was known as triage decision was not properly elucidated. The stakeholder pointed out that triage decision was exclusive for hospital settings.

"Yes, I know. I tell you straightforward, the term that you take is not the usual meaning and you did not explain properly in your project also. The triaging is a process to sort out injured people into different groups based on their need. There is the Oxford definition for triaging" (P8)

"Triaging decision usually in the hospital. It is not even practised in the private medical clinic. I repeated again triaging decision is not even practised the private medical clinic where there is one medical doctor doing it. Ok. Triaging is only found in the hospital set out decision. You are trying triaging decision to a single community pharmacy, I am saying you using the wrong tool to a wrong set out" (P8)
Interestingly, stakeholder P5 pinpointed the government as the main barrier that kept patient-oriented services from being performed in community pharmacy settings.

"For the moment, the government does not trust on CPs. I do not blame them" (P5)

\section{Theme 4: A systematic approach for triaging activities}

All stakeholders had the same opinion that CPs should have a structured and systematic framework to help them to make an accurate triage decision for self-care customers.

"Since this person has been practicing pharmacy only focusing on business so they may be forgotten about what is triaging, how to deal with a patient. Maybe need to remind them. You need to have a system, the easy system for them to follow. It won't be hard anywhere, the chart and everything. Once they got familiar with it, I think it will be very easy" (P1)

"I think definitely it is much better if there is a systematic approach to addressing issues. The form that you developed is a good tool to be used as a thought process for any pharmacists to go through when pharmacists are dealing with customers" (P6)

\section{Theme 5: STARZ-DRP as a systematic approach to making triage decision}

Almost all stakeholders ( $\mathrm{n}=7$ ) had the same opinion that STARZ-DRP was an ideal framework to help CPs to make an accurate triage decision for self-care customers.

"I feel this method is very simple for them to follow. I think it won't be a big problem. They can follow this easily and I think it will be very effective. They should follow this one. It will be very easy to follow and I think it will be very effective. They should stick to their professionalism and this is one of them" (P1)

"This tool can be as a guideline for pharmacists to act as a gate-keeper to screen minor illnesses and claim from an insurance company. I think it is important to cut health care cost because in other countries there is a role for CPs to play in addressing minor ailments so that to reduce the burden on primary health care centre which is much more expensive, of course, it must be done in a proper and organized manner. And like what you have said documentation is also very important because people must be accountable for whatever they have done" (P6)

However, stakeholder P8 had pointed out that STARZ-DRP was not an ideal framework to help CPs to make an accurate triage decision for self-care customers.

"What you do, what you are proposed it to be a structured way of doing it, it has to be realistic. Realistic you have been in the community pharmacy also for $10 y$, you have to know how much time will the patients gave to CPs when they come to see her. Will it be realistic? And also, a lot of CPs may be employed. We have already done the survey, the calculation estimated when we are involved in government, a lot of seminars including reimbursement of the drugs, medication problem and so on. We calculate. The pharmacist's salary and the supporting salary is computed and work out to be quite expensive for us to spend 5-10 min per patient. The government is not going to subsidize the community pharmacies. We have to get that money from the patients. Patients have to pay for it. Are they willing to pay for it? Question 1. Question 2: Do they have time to wait for us to go through all the questions, structured questions of $10 \mathrm{~min}$ ? The answer is ' $\mathrm{NO}$ '. We are not in that situation. It is impossible to carry out. So, it is not a realistic proposal. It may be ok only for study site. But it is definitely cannot be implemented. I will not agree with this so call a structured type, drug-related problem approach in the community. I will not agree on that" (P8)

\section{DISCUSSION}

Currently, GPs are regarding CPs as less capable to perform the role as a primarily health care provider $[19,20]$. Therefore, GPs possess lack of confidence and trust with CPs to take responsibilities to act as an advisor to self-care customers [20]. Furthermore, CPs are also addressing a few barriers to their performance as a primary health 
care provider which are lack of training, time to spend with customers, reimbursement for their additional services, and appropriate framework for performing extended services [21]. As a result, it is noted that most of the stakeholders point out that CPs are paying particular attention to perform business-oriented services rather than patient-oriented services. Such event is also noted in other countries like the United Arab Emirates, Hong Kong, and Singapore when CPs are reported as an entrepreneur instead of as a health care provider [22-25]. In the countries, CPs are confronting some issues such as lack of recognizing as a primarily health care provider $[22,24,25]$ and collaboration with GPs $[24,25]$.

It is noted that all stakeholders have the same opinion CPs should perform more extended roles in community pharmacy settings especially paying attention to perform patient-oriented services. Such potential services pointed out and noted in Malaysia are: (i) medication counselling $[10,11,19,20]$, (ii) weight management counselling [11], (iii) smoking cessation counselling [11], (iv) selfcare counselling [19], (v) monitoring medication therapy plan [19], (vi) distinguish a variety of drug-related problem [19]. It is also noted that CPs in the United Arab Emirates are also making progress to performing smoking cessation, medication therapy review, diabetes care, and self-care counselling [22]. CPs in Canada have an enthusiasm to execute smoking cessation and diabetes care counselling [26]. CPs in Sudan, Russia, and China are performing a medication review in community pharmacy settings [27-29]. CPs in Australia and Belgium are carrying out a medication review for psychiatric patients [30,31]. CPs in Indonesia are having the ability to perform a tuberculosis screening [32]. CPs in India are noted to conduct diabetes and hypertension screening [33]. Such events clearly exhibit CPs' progress towards performing patient-oriented services in community pharmacy settings. Furthermore, at the moment it is noted that GPs and CPs in other countries can work as a team to develop and monitor medication therapy plan for the benefit of their patients [34-36].

Such collaboration between GPs and CPs require a particular framework [11, 26, 28, 37] which can help CPs to distinguish customers who are suitable for self-care treatment and those who require immediate medical attention. Currently, it is noted several counselling frameworks which are WWHAM, AS METHOD, SIT DOWN SIR, ENCORE, CHAPS-FRAPS and QUEST/SCHOLAR [38-43]. Nevertheless, each framework has some limitation as pointed out in another review article [15]. Therefore, STARZ-DRP has been initiated to eradicate the limitation and help CPs to make an accurate triage decision [15]. A study in Malaysia has revealed that STARZDRP is easier to use and CPs take less time to make triage decision [16]. As a result, it is giving a feedback to stakeholder P8 for his doubt about STARZ-DRP. Therefore, almost all stakeholders have the same opinion that STARZ-DRP is an ideal framework to help CPs to make an accurate triage decision in community pharmacy settings.

Interestingly, it is noted that the stakeholders $\mathrm{P} 5$ and $\mathrm{P} 8$ are pointing out government issues as a barrier to CPs' performance as an advisor to self-care customers. The government might not have the interest to give support and advice to CPs to perform the role. Such event is also pinpointed in other countries like the United Arab Emirates, Hong Kong, Singapore, United Kingdom, and Pakistan [22, $24,25,34,44]$. The issue has to be intervened cautiously as it has engaged in an emotional relationship among associations, governing body, and communities. However, the government and communities should empower CPs to perform the role as long as it can benefit the people.

\section{CONCLUSION}

As a conclusion, it is noted that all stakeholders have the same opinion CPs must take the responsibilities to perform a wide range of extended roles such as making an accurate triage decision for selfcare customers in community pharmacy settings. Such extended role need for a particular working relationship with GPs and CPs must have a systematic framework to help them to perform the role. Therefore, STARZ-DRP has been initiated to help CPs to carry out their role. Interestingly, almost all stakeholders pinpoint that STARZ-DRP is an ideal framework for CPs to make an accurate triage decision for self-care customers.

\section{Study limitation}

It is noted that the presidents of the medical associations, as well as the deputy minister of $\mathrm{MOH}$, did not respond to the invitation letter via mail. Their participation in the study might provide additional interesting perspectives and expectations of CPs' role and STARZDRP as a framework to help CPs to make an accurate triage decision.

\section{ACKNOWLEDGMENT}

We are grateful to those who help us to finish up this study.

\section{AUTHOR CONTRIBUTION}

A\#1 conducted, collected and analysed data collection. A\#2 and A\#3 monitored the quality of data collection. A\#2 and A\#3 provided expertise in extra comments.

\section{CONFLICT OF INTERESTS}

The authors declare that they have no conflict of interest to disclose

\section{REFERENCES}

1. Covington TR. Non-prescription medications and self-care. Non-prescription drug therapy: issues and opportunities. Am J Pharm Educ 2006; 70:137.

2. Major C, Vincze Z, Mesko A, Balogh J, Zelko R, Nemeth E. Medicating outside the consulting room. Orv Hetil 2007;148:291-8.

3. Smith M, Bates DW, Bodenheimer T, Clearly PD. Why pharmacists belong in the medical home. Health Affair 2010;29:906-13.

4. Afolabi AO, Akinmoladun VI, Adebose IJ, Elekwachi G. Selfmedication profile of dental patients in ondo State, Nigeria. Nig J Med 2010;19:96-103.

5. Wen Y, Lieber E, Wan D, Hong Y. A qualitative study about self-medication in the community among market vendors in Fuzhou, China. Health Soc Care Comm 2011;19:504-13.

6. Hussain A, Khanum A. Self medication among university students of Islamabad, Pakistan-a preliminary study. Southern Med Rev 2008;1:14-6.

7. Wallace JL. How do NSAIDs cause ulcer disease? Baillieres Best Pract Res Clin Gastroenterol 2000;14:147-59.

8. Horiuchi $T$, Nakamura $M$, Tsuchiya $T$. Contribution of the pharmacists to self-care and primary care with nonprescription medications. Yakugaku Zasshi 2010;130:1623-7.

9. Sing WS. Pharmacy practice in Malaysia. Mal J Pharm 2001;1:2-8.

10. Rajiah K, Kaur KP, Sivarasa S, Ming LY. Perception of community pharmacists towards patient counselling and continuing pharmacy education program in Kuala Lumpur and Selangor states of Malaysia. Am J Pharm Health Res 2014;2:48-56.

11. Hassali MA, Subish P, Shafie AA, Ibrahim MIM. Perceptions and barriers towards the provision of health promotion activities among community pharmacists in the state of penang, Malaysia. J Clin Diagn Res 2009;3:1562-8.

12. Beshir SA, Hanipah MA. Knowledge, perception, practice and barriers of breast cancer health promotion activities among community pharmacists in two districts of selangor State, Malaysia. Asian Pacific J Cancer Prev 2012;13:4427-30.

13. Holland R. When to Refer. Pharmaceutical Society of Australia. Pharmaceutical Society of Australia; 1993. p. 15.

14. Keegan J. The Face of Battle. New York: Viking Press; 1976. p. 267-9.

15. Sarriff A, Nordin N, Hassali MA. STARZ-DRP: a step-by-step approach for pharmacy triage services. Mal J Pharm 2011;1:311-25.

16. Nazri N. Establishing pharmaceutical care service to customers presenting symptoms of minor ailments in community pharmacies in Seberang Prai, Pulau Pinang: a feasibility study. (Thesis) 2014. p. 69-72.

17. Hoddinott SN, Bass MJ. The dillman total design survey method. Can Fam Physician 1986;32:2366-8.

18. Creswell JW, Fetters MD, Ivankova NV. Designing mixed methods study in primary care. Ann Fam Med 2004;2:7-12.

19. Azmi S, Nazri N, Azmi AH. Extending the roles of community pharmacists: views from general medical practitioners. Med J Malaysia 2012;67:574-8.

20. Hassali MA, Awaisu A, Shafie AA, Saeed MS. Professional training and roles of community pharmacists in Malaysia: 
views from general medical practitioners. Malays Fam Physician 2009;4:71-6.

21. Saw PS, Nissen LM, Freeman C, Wong PS, Mak V. Health care consumers' perspectives on pharmacist integration into private general practitioner clinics in Malaysia: a qualitative study. Patient Prefer Adherence 2015;9:467-77.

22. Rayes IK, Hassali MA, Abduelkarem AR. The role of pharmacists in developing countries: the current scenario in the United Arab Emirates. Saudi Pham J 2015;23:470-4.

23. Rayes IK, Hassali MA, Abduelkarem AR. Perception of community pharmacists towards the barriers to enhanced pharmacy services in the healthcare system of Dubai: a quantitative approach. Pharm Pract 2015; 13:506.

24. Wong FYY, Chan FWK, You JHS, Wong ELY, Yeoh EK. Patient self-management and pharmacist-led patient self-management in Hong Kong: a focus group study from different healthcare professionals' perspectives. BMC Health Serv Res 2011;11:121.

25. George PP, Molina JAD, Cheah J, Chan SC, Lim BP. The evolving role of the community pharmacist in chronic disease management-a literature review. Ann Acad Med Singapore 2010;39:861-7.

26. Laliberte MC, Perreault S, Damestoy N, Lalonde L. Ideal and actual involvement of community pharmacists in health promotion and prevention: a cross-sectional study in Quebec, Canada. BMC Public Health 2012;12:192.

27. Salim AM, Elgizoli B. Exploring self-perception of community pharmacists of their professional identity, capabilities and role expansion. J Res Pharm Pract 2016;5:116-20.

28. Egorova SN, Akhmetova T. Pharmaceutical counselling: between evidence-based medicine and profits. Int J Risk Saf Med 2015;27 Suppl 1:87-8.

29. Fang Y, Yang S, Zhou S, Jiang M, Liu J. Community pharmacy practice in China: past, present and future. Int J Clin Pharm 2013;35:520-8.

30. Berbatis CG, Sunderland VB, Joyce A, Bulsara M, Mills C. Enhanced pharmacy services, barriers and facilitators in Australia's community pharmacies: Australia's National Pharmacy Database Project. Int J Pharm Pract 2007;15:185-91.

31. Scheerder G, De Coster I, Van Audenhove C. Pharmacists' role in depression care: a survey of attitudes, current practices, and barriers. Psychopharmacol Serv 2008;59:1155-61.
32. Khairunnisa, Nasution A. Pharmacists' perception about their roles in tuberculosis control program in Medan, Indonesia. Asian J Pharm Clin Res 2017;10:256-8.

33. Sushilkumar PL, Mahendrakumar BJ, Baishnab S, Gloria Sam K, Chaitanya Kumar T. Implementation and evaluation of health screening services to diabetic and hypertensive patients in a selected community pharmacy at Belgaum City. Asian J Pharm Clin Res 2015;8:305-15.

34. Warchal S, Brown D, Tomlin N, Portlock J. Attitudes of successful candidates of supplementary prescribing courses to their training and their extended roles. Pharm J 2006;276:348-52.

35. Hoti K, Hughes J, Sunderland B. An expanded prescribing role for pharmacists-an Australian perspective. Aust Med J 2011;4:236-42.

36. Malangu N. The future of community pharmacy practice in South Africa in the light of the proposed new qualification for pharmacists: implications and challenges. Global J Health Sci 2014;6:226-33.

37. Sadek MM, Elnour AA, Al Kalbani NMS, Bhagavathula AS, Baraka MA, Aziz AMA, et al. Community pharmacy and the extended community pharmacist practice roles: The UAE experiences. Saudi Pharm J 2016;24:563-70.

38. Blenkinsopp A, Paxton P, Blenkinsopp J. Symptoms in the pharmacy: a guide to the management of common Illness. $5^{\text {th }}$ Eds. Blackwell Publishing, Oxford UK; 2005. p. 1-13.

39. Edwards C, Stillman P. Minor illness or major disease? The clinical pharmacist in the community. $4^{\text {th }}$ Eds. Pharmaceutical Press London; 2006. p. 1-10.

40. Rutter P. Community pharmacy. Symptoms, Diagnosis and Treatment. Churchill Livingstone. An Imprint of Elsevier Limited; 2004. p. 9-11.

41. Rutter PM, Horsley E, Brown DT. Evaluation of community pharmacists' recommendations to standardize patient scenarios. Ann Pharmacother 2004;38:1080-5.

42. McCallian DJ, Cheigh NH. The pharmacist's role in self-care. J Am Pharm Assoc 2002;42(5 Suppl 1):40-1.

43. Shauna MB, Kirby J, Conrad WF. A structured approach for teaching students to counsel self-care. Patients Am J Pharm Educ 2007;71:1-7.

44. Saira A, Mohamed Azmi H, Mohamed Izham MI, Maqsood A, Imran M, Asrul AS. The role of pharmacists in developing countries: the current scenario in Pakistan. Hum Resour Health 2009;7:54. 